\title{
Enfrentar el sufrimiento social y la tarea de la sociología: Las paradojas del desarrollo local sustentable
}

\author{
María Emilia Tijoux*
}

¿Qué es lo que sostiene a la vida social? ¿Cómo consigue la gente mantenerse en pie ante las actuales condiciones que el capitalismo neoliberal le pone a La vida? ¿Lo hace al "interior" mismo de la sociedad "normal", conformada por mujeres y hombres integrados o a lo menos insertos en los actuales procesos de intercambios económicos y culturales? ¿O hay individuos que se sustentan también pero sobreviviendo al margen de procesos "autorizados", remando a contracorriente, resistiendo? Algunas de estas preguntan las hacían ya los sociólogos clásicos en el siglo XIX ante el crecimiento económico, el caos que llegaba del desarrollo, el aumento de la densidad moral y las modernizaciones ${ }^{1}$.

Hoy, estos problemas se han agudizado. Ya no parece posible pensar la sustentabilidad de un desarrollo que tan desigualmente se da. El "desarrollo local susentable" se deshace en ambigüedades que lo vuelven confuso y su referencia ya no apela al carácter crítico que antes solía concitar.

He querido para esta intervención reflexionar sobre la sustentabilidad a partir de lo que experimentamos en el vivir chileno; los conceptos, no solo son sociales, tienen vida social y se muevan al ritmo de singularidades, los "vemos" en situaciones y hablas concretas, en lugares específicos. Pueden ser paradójicos y engañosos.

El desarrollo refiere cuantitativamente al crecimiento como continuidad de La evolución de situaciones económicas y cualitativamente al mejoramiento Del bienestar del conjunto de una población y al progreso de su estado social. Su aspecto puramente cuantitativo - lleno de significaciones - implica que previa y simultáneamente han aumentado los flujos de materias primas, de bienes y servicios en el proceso productivo. Pero ese crecimiento es también extensión de flujos mercantiles, de una mayor extracción de recursos naturales y de la rápida transformación de valores de uso en valores de cambio. La consecuencia de este crecimiento es una mayor y mejor utilización de "los recursos naturales y culturales" con fines económicos: se van a invertir, a explotar y a "rentabilizar" conjuntamente los patrimonios naturales y culturales. Los valores de uso colectivo se traspasan al mercado que los somete a su lógica, mostrando que el imperio de lo económico en nada asegura la reproducción del medio natural.

Desde la Revolución Industrial, el crecimiento - regular o no - , ha sido un fenômeno de tendencia constante, que puede interpretarse globalmente como la extensión del mercantilismo que periódicamente integra elementos exteriores a la economía, cuestión que se amplifica con la manera de consumir que transforma lãs relaciones entre los individuos y las cosas, entre los individuos y los individuos, entre los individuos y la sociedad y entre las cosas mismas. Las cosas ahora hablan, se multiplican, se banalizan, compiten entre sí.

La diferenciación social forzosamente se dará en la lucha entre los individuos por poseer las cosas que simbolizan el éxito. El crecimiento entonces, tiene un carácter espacial, es estructuralmente expansionista y el desarrollo podrá claramente caracterizarse por la adopción de una manera de consumir y de un tipo de relaciones sociales inspiradas de países dominantes. El resultado es la tendencia inevitable a la homogenización pronunciada de estos modos de consumo específico, en desmedro de todas las culturas locales.

En cuanto a su dimensión cualitativa, el desarrollo corresponde a un crecimiento desigual del bienestar de la población que modifica las situaciones y las vivencias de los individuos,

\footnotetext{
* Professora da Universidade Bolivariana do Chile
} 
la estructura social y la estructura mental. La situación objetiva de "mayor bienestar" embrolla la existencia para "ser-más", como deseo problema que transforma. "Sentirse mejor ${ }^{2}$ y distinto(a)" involucra capitales culturales, sociales, simbólicos, además de los económicos, que deben saberse usar para disputar los múltiples campos de posicionamientos donde se pretende permanecer. Las teorías económicas entonces pueden ser vistas como casos particulares de una teoría más general de la economía de las prácticas ${ }^{3}$ que permiten comprender mejor las posiciones en los mercados que se abren y cierran ${ }^{4}$.

Lo local tiene connotaciones opuestas. Invoca territorios, espacios de vida, lugares de características particulares, calificados por su emplazamiento, disposición, singularidad. Afecta a grupos circunscritos, a conocedores de sus historias, SUS secretos, sus envolturas específicas. No es generalizable. Se caracteriza por su unicidad, por su especificidad estructural y espacial que encuentra coherencia en el territorio y, su lógica no reside en la antinomia de una reproducción. Lo local no induce al crecimiento porque su riqueza es la combinación de factores de origen natural o cultural, como la preservación (aun con explotación) y la patrimonialización. "Reproducir lo local" es el sueño de conservación o de reproducción de patrimonios específicos del esfuerzo colectivo por la singularidad y la voluntad de heterogenización.

Las lógicas del desarrollo y de lo local surgen como lógicas antagónicas y su cercanía puede entenderse como una paradoja, cuando el desarrollo supone que la racionalidad es la condición necesaria para reproducirse por extensión y lo local involucra más bien un "sentimiento" que invita al refugio, a la identidad Del territorio, a la conservación de historias particulares, a las redes de defensa. Su cercanía podría entenderse o ser de otro modo solo con la invención de un enfoque donde lo que se haga para ganar no conduzca a perder lo ganado. Solo quienes poseen ese saber específico podrían dar las pautas.

Desarrollo loca, es un concepto que durante un tiempo se legitimó por haberse presentado como alternativa a las políticas de desarrollo de las autoridades centrales en períodos de crisis. Hace algunos años inspiró numerosas iniciativas de asociaciones y grupos sociales. Actualmente se ha cubierto de significaciones y contradicciones a causa de un uso diversificado y conveniente.

El desarrollo sustentable en su actual acepción viene del debate internacional iniciado del año 1972 en Estocolmo y consolidado veinte años después en Río de Janeiro. Muchas interpretaciones han hecho las ciencias sociales, pero casi todas son únicamente variaciones de la definición sugerida por la Comisión Mundial sobre Medio Ambiente y Desarrollo de 1987: "El desarrollo sustentable es aquel que satisface las necesidades de las generaciones presentes, sin comprometer la capacidad de las generaciones futuras para satisfacer sus propias necesidades". La importancia de esta definición es considerar a los seres humanos como principal eje del proceso de desarrollo, sin embargo a causa de sus contradicciones, habría que buscar un nuevo estilo, ambientalmente sustentable, para que la sociedad acceda y haga uso de los recursos naturales al mismo tiempo que preserva la biodiversidad.

La historia del concepto de desarrollo sustentable tuvo una dudosa evolución y un uso múltiple que se explica por los distintos intereses puestos en el juego. Los conceptos al comienzo atraen por su novedad y después de hacerse famosos se allegan al lenguaje cotidiano de las instituciones y el mercado. Destacamos la propuesta de A. Elizalde ${ }^{5}$ de introducir un criterio crítico en el abordaje de la sustentabilidad, que transite hacia una cosmovisión distinta del concepto: "el cambio fundamental de realizar no está en el plano de la tecnología, ni de la política o de la economía, sino que está radicado en el plano de nuestras creencias, son ellas las que determinarán el mundo que habitemos". Las naciones industrializadas consumen utensilios domésticos, energía y materiales cada vez más sofisticados que suelen destruir el medioambiente y las bases de recursos naturales. Inversamente, miles de personas de regiones marginadas luchan para comer, habitar y abrigarse, exponiéndose a graves problemas de salud, a la ignorancia y con ella, a la imposibilidad de comprender lo que les ocurre. Si bien se advierten esfuerzos destinados a propuestas tecnológicas que reduzcan el daño al medioambiente y que aumenten la eficiencia del uso de materiales y energía, no son suficientes. 
Transitar hacia la sustentabilidad implica la comprensión integral y diferenciada Del funcionamiento de los sistemas de producción/consumo y simultáneamente una preocupación particular por sectores mayoritarios que quedan al margen de las decisiones. No es "el mercado", como algo intangible y lejano el responsable del sufrimiento social, es demasiado fácil que cualquiera lo nombre para culparlo. El mercado es resultado de "algo", es una producción de "alguien" que contiene mecanismos, dispositivos, creencias, cosas... Y busca un efecto sobre muchos "alguienes". En este contexto, las ciencias sociales pueden comenzar por identificar los medios que consiguen construir aspiraciones, deseos individuales e ilusiones colectivas: los medios de comunicación, las instituciones sociales, los grupos de poder entre otros.

¿Cómo y quienes crean las "necesidades" materiales? ¿Cuáles son los elementos que construyen el comportamiento de sobre-consumo? ¿Qué políticas ayudan a separar la mejoría en el bienestar del aumento del consumo de energía y materiales? ¿Qué herramientas, qué metodologías fortalecen los estudios comparativos de producción/consumo?

La metodología de la Huella Ecológica en Chile ${ }^{6}$ y el Programa de Economia Ecológica del Instituto de Ecología Política, calculó que los habitantes de la comuna de Vitacura usan 22,4 hectáreas por habitante año, mientras que en la comuna de Cerro Navia los habitantes necesitan anualmente 1,3 hectáreas, es decir 17 veces menos. La diferencia mayor, está dada entre otros factores, por el alto consumo de energía y combustibles de Vitacura. Entonces, si la defensa del privilegio de una minoría posterga las soluciones reales, no habrá paz ni oportunidad real para que avancen los países menos desarrollados y los privilegios se mantendrán a costa de la fuerza y la violencia. Por otra parte, la biodiversidad como la base sobre la que se constituye la estabilidad de los ecosistemas planetarios seguirá deteriorándose, aumentando peligrosamente la estabilidad del hábitat de todas las especies ${ }^{7}$.

Las condiciones de vida, - favorecidas o inducidas por la creatividad del mercado y los deseos individuales de ingresar en distintos campos de la competencia o dominación -, muestran un modo de consumir forjado en la fragmentación y en la individualización. La promesa "global" ha abierto la sociedad chilena al mundo y há producido/ potenciado en las personas la ilusión de integración y movilidad social (bienestar social). El mercado con su creatividad infinita, condiciona las opciones individuales y colectivas, generando un sistema de construcción de identidades para diversos grupos etarios, de género, de ingreso, etc., aglutinados en campos específicos que él domina.

Trabajadores clasificados por sus salarios, sus condiciones socioeconómicas, sus territorios, sus escuelas, sus tiempos de entretención y sus propias historias, organizan sus existencias a partir de los ingresos. El trabajo, implica "estar en el mundo" y cuando no hay bienes, vincula con la existencia, es la acción y el reconocimiento que permite vivir y participar en las redes de sociabilidad, tal como lo afirma R. Castel. Pero cuando se hace inconstante y no se avizora en el porvenir como seguridad que permita enfrentar la vida, dejamos de formar parte de una colectividad que nos reconozca y considere. Nos adviene el golpe de la doble inseguridad de no poder enfrentar, ni la existencia, ni la mirada reprobadora de los demás. Cuando el trabajo es precario vivimos la vida en plazos cortos, de a pedazos, el futuro se resquebraja y el tiempo se vuelve loco.

De-conversión, individualismo negativo, vulnerabilidad, desafiliación, precarización son características de la sociedad de hoy. El riesgo ya "está" en la vida. Hemos pasado de un individualismo colectivo a uno negativo, sacudiéndonos del primero para cubrirnos con la des-individualización cuyo resultado es la inseguridad y la desprotección. En este mismo punto, claramente, un modo de participar en la vida social es la posesión de cosas, que terminan por hipotecar la vida misma ${ }^{8}$.

No hay misterio en que la "globalización" se expanda, al punto que parece impensable observar y comprender los hechos y las relaciones sociales fuera de su prisma. En Chile no es 
algo nuevo, ha madurado y se ha solidificado después de pasar por un proceso que construyó cuidadosamente las herramientas para favorecer al poder político-económico. Preocupa ver a nuestra sociedad en un estado adormecido, sintiendo y viviéndola como la panacea que abre al mundo. Lo que ha sucedido no se dio, ni de la noche a la mañana, ni bajo condiciones de un consentimiento aceptable. El laboratorio neoliberal que somos, emplazado sobre la base de la catástrofe individual y colectiva de muchos chilenos, sí se dio las condiciones para las fases que precisaba con el fin de privatizar al país y construir subjetividades que sostenían dicho fin, procurándose una racionalidad organizada cívico-militarmente que reprimió masivamente a los movimientos sociales, prohibió los partidos políticos y practicó el exterminio selectivo contra toda una generación. La "revolución neoliberal chilena" logró madurar primero, a diferencia de los neoliberalismos tardíos como ocurrió en Argentina, Ecuador y Perú.

Hoy, la fuerza del capitalismo neoliberal, maduro y seguro, ha conseguido clausurar la sociedad hasta hacerle tragar su patología temerosa y conformista como algo normal. Las reacciones más "sentidas" se dan frente a problemas que el capitalismo mismo pone en un lugar de importancia: la seguridad ciudadana y el reflejo de protegerse de las "clases peligrosas", resurge. El capitalismo y sus defensores modifican convenientemente las políticas estatales y el rostro de la sociedad, para a partir de las "violencias urbanas" o "violencias sociales" se ponga a funcionar un control que moviliza a policías y civiles a una intensa vigilancia de los sectores pobres, reprimiendo sus prácticas de resistencia económica y los desórdenes con características políticas. La causa del temor está en la presencia de individuos precarizados, o sea, en la figura de la pobreza.

Chile crece, tiene un desempleo relativamente bajo y éxitos macro-económicos que demuestran el triunfo de un proyecto. Los costos de esa ganancia se ven en los niveles de desigualdad que aumentan con ese crecimiento. Sin embargo, aún en su diferencia con los movimientos sociales de antaño, hay múltiples grupos que luchan de modo fragmentario: jóvenes, estudiantes deudores de sus universidades, deudores habitacionales, trabajadores precarizados, trabajadores sin empleo, mujeres solas que bogan por sobrevivir, minorías sexuales, minorias étnicas defensores del medio ambiente, niños trabajadores, jubilados empobrecidos, inmigrantes, entre tantos otros.

\section{III}

Las ciencias sociales pueden ser subversivas. Y si aún no lo son, se puede inventar un pensamiento social que reconozca la fragmentación y la tradición de un universo donde hay acuerdo entre las actitudes subjetivas y las estructuras sociales, pero un pensamiento que busque, con una voluntad más férrea, superar las dicotomías objetivismo-subjetivismo, (la más funesta $a^{9}$; material-simbólico; teoría-empiria; holismo-individualismo. Más que pensar la sociedad desde la "globalización" hay que hacerlo desde el prisma de la dominación observada en las prácticas sociales más cotidianas. De este modo podemos objetivar las relaciones de dominación, develando sus mecanismos y entregando herramientas intelectuales y prácticas para cuestionar aquella (su) legitimidad que nos supera ${ }^{10}$.

Es necesaria la reserva de un "saber" que atraviese los obstáculos que le impiden crecer y comprender al mundo. Quienes buscamos lo que allí ocurre tenemos que darnos por tarea mostrar un saber que existe en la gente, para desarmar lo que ha sido armado velando sus realidades cotidianas. Los investigadores laboramos en el espacio del conocimiento para dar cuenta lo que se oculta tras las miserias expuestas como "dadas", ejecutando así un acto político verdadero que enfrente a quienes construyen la discriminación y la criminalización. Si logramos objetivar un acto político con esta decisión, habremos vinculado lo político con el enfoque científico que implementamos al "hacer investigación". Así conseguiremos que la "gran teoría" tenga sentido cuando se enfrenta con objetos de estudio empírico ${ }^{11}$.

El trabajo analítico, al deshacer las representaciones de estos "malestares" y reconstruirlos como problemas específicos, se erige contra la visión mediática y contra la visión política. La primera está siempre predispuesta a fabricar acontecimientos y estigmas para preparar a la 
segunda a propuestas que la atrapan, como ocurre con las políticas públicas hechas desde los informes de expertos. Ambas visiones ocultan y contribuyen a la producción del sufrimiento social y ambas producen palabras sobre el sufrimiento privando al sufrimiento de palabra. Las Ciencias sociales tienen mucho por hacer y la sociología, por su propia constitución, debe cumplir un rol crítico que enfrente a los paradigmas dominantes. De esta manera podremos asegurar que la sustentabilidad solo está en manos de la sociedad. Nos corresponde hacer todo lo posible para que pueda pensarse a si misma y construir desde ese pensar el saber que necesita.

\section{Notas}

${ }^{1}$ Ver Durkheim; Emilio en La División del trabajo social.

${ }^{2}$ En sentido amplio, como la salud física que objetiva al sentimiento en el sentir real de un cuerpo que sufre dolor por ejemplo. Luego sentirse mal por el hecho de sentirse mal de salud, se vuelva pan de todos los días.

3 "Espace social et génèse de "classes", citado por Bonnewitz, en: Actes de la recherche em sciences sociales, n. 52-53, 1984, p. 3 y 9, (Trad. por Tijoux, M.E.).

${ }^{4}$ A este respecto vale considerar en Chile lo ocurrido a partir de las privatizaciones con el mercado de la educación y el de la salud.

${ }^{5}$ Elizalde, Antonio (1992) “Desarrollo y Sustentabilidad: límites y potencialidades. (Una mirada desde la perspectiva del Sur)" en Documentación Social. Revista de Estudios Sociales y de Sociología Aplicada. n. 89, Octubre - Diciembre de 1992, Madrid.

${ }^{6}$ El cálculo de la Huella Ecológica es un instrumento utilizado para la planificación territorial y para buscar solución a los problemas de sobreconsumo, pero además se usa como indicador biofísico para generar un nivel de consciencia real y al mismo tiempo para estimular respuestas que consideren la crisis que se genera al vivir fuera de los límites establecidos por los ecosistemas.

${ }^{7}$ Wackernagel, M y Rees, W., Nuestra huella ecológica, Editorial LOM, Santiago, 2001.

${ }^{8}$ A este respecto es interesante relatar lo que ocurre en Chile con un hecho muy particular en la educación y que se denomina "congelar los estudios", situación que experimentan miles de jóvenes que ingresan a la universidad y que no pueden en un momento del proceso, continuar cancelando las mensualidades.

${ }^{9}$ Bourdieu, P: Choses dites, Minuit, París, 1987, p. 149.

${ }^{10}$ Bonnewitz, P: Premières leçons sur, La sociologie de Pierre Bourdieu, PUF, París, 1998.

${ }^{11}$ Comprender es crear las condiciones para neutralizar la violencia simbólica ya contenida en la relación de comunicación. Cada discurso es particular, por eso entrega los elementos que necesita su propia explicación, pero ella no puede solo darse desde y con la palabra. Hay que construir y/o poner en práctica herramientas que entreguen las condiciones de inteligibilidad. Un solo ejemplo: reconstruyendo las condiciones de producción de las entrevistas, o la producción de la palabra, se remedian los polémicos efectos de objetivaciones parciales y se restituye su parte de verdad, para escapar a las trampas del relativismo. Trabajar para la comprensión implica una suerte de composición de todo un trabajo (obra) que participa del método.

\section{Referências}

BONNEWITZ, Patrice. Actes de la recherche em sciences sociales. [s.1.], n. 52-53, 1984, p. 3 y 9. (Trad. por Tijoux, M.E.). . Premières leçons sur. La sociologie de Pierre Bourdieu. París: PUF, 1998.

BOURDIEU, P. Choses dites. Minuit. París, 1987, p. 149.

DURKHEIM, Emile. La División del trabajo social. 2.ed. Buenos Aires: Schapire, 1967.

ELIZALDE, Antonio. Desarrollo y Sustentabilidad: límites y potencialidades. In: Documentación Social. Revista de Estudios Sociales y de Sociología Aplicada. n. 89, Octubre - Diciembre de 1992, Madrid.

WACKERNAGEL, M y Rees, W., Nuestra huella ecológica, Editorial LOM, Santiago, 2001.

WACKERNAGEL, Mathis; REES, William . Nuestra huella ecológica: Reduciendo el impacto humano sobre la Tierra. Santiago: IEP/LOM Ediciones, 2001. 